\title{
Monitoring trends in sexual behaviour and HIV/STIs in Peru: are available data sufficient?
}

\author{
C F Cáceres, W Mendoza
}

Sex Transm Infect 2004;80(Suppl II):ii80-ii84. doi: 10.1136/sti.2004.012021

See end of article for authors' affiliations .....................

Correspondence to: Professor C F Cáceres, School of Public Health, Cayetano Heredia University, Av Armendariz 445, Southern Campus, Lima 18, Peru;

ccaceres@upch.edu.pe

Accepted for publication 6 September 2004

\begin{abstract}
Objectives: To review and summarise various types of Peruvian evidence on sexual behaviour, HIV/STI exposure and risk, and discuss how to increase its usefulness for HIV/STI risk trend monitoring in Peru. Methods: Review HIV sentinel surveillance conducted by the Ministry of Health; data from the Demographic and Health Surveys (DHS); and academic publications on sexual behaviour in combination with biological markers. Changes over time, quality of data, size of studies, and intended audience are discussed.

Results: Data from HIV sentinel surveillance showed very high (8-23\%) HIV seroprevalence among men having sex with men, but stable, relatively low figures among female sex workers (1\%) and antenatal clinic patients (under $0.5 \%$ ). DHS data suggest that single women increased their sexual activity throughout the 1990s but did not raise their contraceptive use accordingly, resulting in increased early conceptions. The contribution of condoms to overall contraceptive protection increased threefold in 1992-2000. According to the 1996 survey, men become sexually active 2.5 years earlier than women, but marry or cohabit four years later than women; women marry or cohabit 1.5-2.5 years after first sex, whereas men take eight years to do so. Finally, published studies confirmed dramatic differences in HIV prevalence between men who have sex with men and other populations, and also suggested patterns of bridging from men to women.

Conclusions: Data available from the three sources are numerous, although limitations of each approach reduce their monitoring utility: Ministry of Health studies should select better sentinel populations and timely process behavioural data. Future demographic surveys should incorporate an AIDS risk perspective and include men.
\end{abstract}

$\mathrm{T}$ echnological developments and the evolving history of the AIDS pandemic have changed information needs for monitoring trends and providing feedback to HIV control strategies. Second generation surveillance of $\mathrm{HIV}^{1-3}$ recognises the limitations posed by traditional AIDS case notification and recommends collection of various types of data to better understand trends in epidemics-for example, HIV prevalence (as measured through both surveys and sentinel studies), the prevalence of sexually transmitted infections (STIs), and sexual practices posing risk. All those indicators can be obtained for both the general population and specific groups. The continuous development of laboratory techniques to detect exposure to STIs or actual infection has been particularly helpful in this regard.

Surveys on sexual behaviour implemented in the HIV era, which often incorporated the measurement of biological indicators, implied mixed method approaches which crossed disciplinary boundaries. Neither the approach of infectious disease epidemiologists (with their emphasis on field laboratory tests and short focused interviews) nor that of demographers (focused on fertility, child mortality, and contraceptive use in heterosexual unions) were entirely appropriate to explore in detail people's sexual practices, particularly those considered less conventional. A new interdisciplinary field of HIV related survey research has evolved over recent years.

The purpose of this paper is to identify and analyse, in Peru, various sources of data on sexual behaviour, HIV/STI exposure, and risk, from epidemiological surveillance to demographic studies and academic research; to summarise their findings; and to assess how the information they currently provide can be improved for HIV behavioural risk monitoring purposes.

\section{METHODS}

The main forms of data collection on HIV prevalence and/or sexual behaviour relevant for HIV control planning, generated in Peru in the past decade, are as follows:

- HIV sentinel surveillance conducted by the Ministry of Health $(\mathrm{MoH})$ : biological surveillance in some groups, mixed surveillance in others, behavioural only in one.

- Behavioural data from three rounds of the Demographic and Health Surveys (DHS), plus other studies conducted by the National Institute of Statistics and Computer Science (INEI).

- Academic studies on sexual behaviour in combination with biological markers.

In our discussion we will keep in mind dimensions such as changes over time, quality of data, size of studies, and the audience for which these data are gathered and analysed.

\section{RESULTS}

Sources of data on sexual behaviour and STI markers in the last decade in Peru are numerous, probably as a result of the existence of a strong epidemiology unit with a focal point on HIV/STI in the MoH, regular implementation of DHS by the INEI, and the existence of local researchers working on HIV issues with international research groups. Not all of this information has, however, been adequately processed or, more so, actually used.

Abbreviations: ANC, antenatal clinic; DHS, Demographic and Health Surveys; FSW, female sex worker; INEI, National Institute of Statistics and Computer Science; MoH, Ministry of Health; MSM, men who have sex with men. 


\section{HIV and sexual risk surveillance at the Ministry of Health}

The MoH started HIV related surveillance in the early 1990s. For a long time, AIDS cases reporting data (plus some notification of HIV infections) were the only type being collected. In the late 1990s sentinel studies began, focusing mainly on antenatal clinic (ANC) clients aged 15-24 years (serological testing only) as well as on various vulnerable populations such as female sex workers (FSWs), men who have sex with men (MSM), imprisoned populations, clients of FSWs, and STI clinic clients (combined biological/ behavioural data collection), and females undergoing mandatory military reserve registration (behavioural data collection only). ${ }^{4}$ In studies with FSWs and MSM, convenience samples based on outreach work at commercial sex and cruising areas, as well as STI clinic clients, have been used; participation required informed consent and subjects received their test results with pre- and post-test counselling. Limited staff time for the most part has prevented the analysis of behavioural information, such that most published data are restricted to the prevalence of HIV and other STIs. Figure 1 shows HIV prevalence estimates for population groups for which two or more estimates have been generated through sentinel surveillance; single HIV prevalence estimates exist for STD clinic patients $(7 \%, 1996)$, prisoners $(1.1 \%, 2000)$, and FSWs' clients $(1 \%, 2002)$

These data confirm that HIV in Peru is concentrated in populations of MSM, because HIV prevalence in this group is above 5\%, whereas it is below $1 \%$ in ANC clients and below $5 \%$ in other traditionally vulnerable groups. A trend towards stabilisation in ANC clients and FSWs is evident. Trends in HIV among MSM in both Lima and the provinces are still unclear, given the potentially high variability of participants' profiles over time (for example, involvement in prostitution, number of partners, and poverty level). ${ }^{4}$

\section{DHS and other studies conducted by INEI}

Peru has a strong tradition of nationally representative demographic surveys. The last two major nationally representative studies - the DHS conducted in $1996^{5}$ and $2000^{6}$ included new modules on knowledge of HIV/AIDS and other sexually transmitted diseases (STDs), prevention, and risk perception. In addition, survey samples became larger, enhancing both their national and regional representativeness. This approach made it possible to consider important

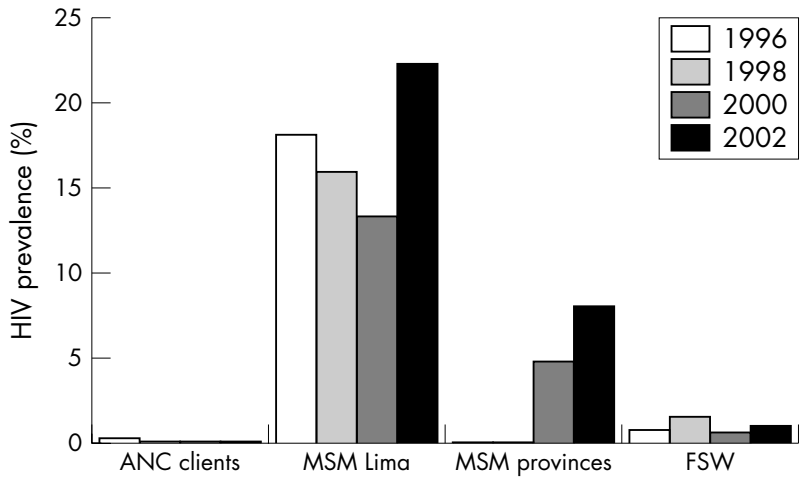

Figure 1 HIV prevalence from sentinel surveillance in various populations.

regional differences, ${ }^{7}$ from which distinct prevention strategies and policy measures should derive.

We explored the DHS reports for $1992,{ }^{8} 1996,{ }^{5}$ and $2000^{6}$ in Peru for variables particularly sensitive to an assessment of behavioural risk for HIV/STI. One obvious limitation is the fact that, even until 1996, the condom was perceived mainly as a contraceptive method. The 1996 survey enquired about condom use at last sexual intercourse with spouse among women who had had sex in the year before the interview, while the 2000 survey introduced questions on condom use with non-cohabiting partners and with any partner (see table 1 ). In table 1 the most interesting finding is that, of respondents in the 2000 report, women use condoms 2-4 times more frequently with non-cohabiting partners, and that this difference is more evident in younger age groups. Frequency of condom use with non-cohabiting partners is also 50\% higher among single, sexually active women, compared with married or cohabiting women.

Another indicator of interest, also available for 1992, is the proportion of women who report sexual activity in the last four weeks. Table 2 includes this variable as well as the proportion of women who were married or cohabiting. As shown, the proportion of women with recent sexual activity parallels the proportion of married/cohabiting women until the 30-39 year age groups, where the former starts to decline and the latter stabilises around $75-80 \%$. From the 2000 DHS data in table 1 , however, we presume that a proportion of

Table 1 Condom use at last sexual intercourse by type of partner, among women who had sex during 12 months prior to survey

\begin{tabular}{|c|c|c|c|c|}
\hline & \multirow{2}{*}{$\begin{array}{l}1996 \\
\text { Used condom } \\
\text { with spouse, } \\
\% \text { (n) }\end{array}$} & \multicolumn{3}{|l|}{2000} \\
\hline & & $\begin{array}{l}\text { Used condom } \\
\text { with spouse, } \\
\%(n)\end{array}$ & $\begin{array}{l}\text { Used condom with } \\
\text { non-cohabiting } \\
\text { partner, \% (n) }\end{array}$ & $\begin{array}{l}\text { Used condom } \\
\text { with any partner, } \\
\% \text { (n) }\end{array}$ \\
\hline \multicolumn{5}{|l|}{ Age group (years) } \\
\hline $15-19$ & $5.7(556)$ & $3.2(594)$ & $15.0(441)$ & $8.3(1030)$ \\
\hline $20-24$ & $6.2(2144)$ & 5.9 (2004) & $22.2(629)$ & $9.8(2630)$ \\
\hline $25-29$ & $6.4(2821)$ & $8.2(2770)$ & $24.3(446)$ & 10.5 (3206) \\
\hline $30-39$ & $6.3(5536)$ & $6.7(5877)$ & $12.1(499)$ & $7.1(6360)$ \\
\hline $40-49$ & 4.5 (3379) & 6.1 (4222) & 10.7 (198) & $6.3(4414)$ \\
\hline \multicolumn{5}{|l|}{ Marital status } \\
\hline $\begin{array}{l}\text { Married or } \\
\text { cohabiting }\end{array}$ & $5.8(14435)$ & $6.6(15181)$ & $13.2(57)$ & $6.6(15204)$ \\
\hline $\begin{array}{l}\text { Divorced, separated, } \\
\text { widowed }\end{array}$ & NA & NA & $13.0(586)$ & NA \\
\hline $\begin{array}{l}\text { Single, had } \\
\text { intercourse }\end{array}$ & NA & NA & $19.8(1570)$ & NA \\
\hline
\end{tabular}


Table 2 Women who were married (cohabiting) and who reported sexual activity in past four weeks

\begin{tabular}{|c|c|c|c|c|c|c|}
\hline \multirow{2}{*}{$\begin{array}{l}\text { Age } \\
\text { group } \\
\text { (years) }\end{array}$} & \multicolumn{2}{|l|}{1992} & \multicolumn{2}{|l|}{1996} & \multicolumn{2}{|l|}{2000} \\
\hline & $\begin{array}{l}\text { Married } \\
(\%)\end{array}$ & $\begin{array}{l}\text { Sexually } \\
\text { active (\%) }\end{array}$ & $\begin{array}{l}\text { Married } \\
(\%)\end{array}$ & $\begin{array}{l}\text { Sexually } \\
\text { active (\%) }\end{array}$ & $\begin{array}{l}\text { Married } \\
(\%)\end{array}$ & $\begin{array}{l}\text { Sexually } \\
\text { active (\%) }\end{array}$ \\
\hline $15-19$ & 9.6 & 11.3 & 11.9 & 11.4 & 10.3 & 11.5 \\
\hline 20-24 & 40.8 & 39.6 & 47.6 & 44.3 & 41.6 & 41.4 \\
\hline $25-29$ & 67.8 & 63.5 & 70 & 62.5 & 64.9 & 61.2 \\
\hline $30-34$ & 78.1 & 71.7 & 80.8 & 71.3 & 76.7 & 70.5 \\
\hline $35-39$ & 81.3 & 73.9 & 80.9 & 71.4 & 78.7 & 69.2 \\
\hline $40-44$ & 81.2 & 71.1 & 80 & 65.8 & 81 & 67.2 \\
\hline $45-49$ & 79.5 & 65.9 & 80.2 & 58.3 & 75.9 & 57.2 \\
\hline Total & 55.1 & 50.7 & 58.3 & 50.8 & 56.1 & 50.4 \\
\hline
\end{tabular}

sexual activity among women in each age group takes place with non-cohabiting partners.

Ali et al have recently conducted a very comprehensive analysis of the reproductive behaviour of single women aged 15-24 years in Colombia and Peru between 1986 and 2000. For Peru they used data from the same three DHS surveys as this study, all of which collected detailed contraceptive histories for the preceding five years. This information, together with reported age at first intercourse, allows an analysis of annual trends in the proportion of time spent in the following states: virgin; sexually active and not using contraceptives; sexually active and using contraceptives; and "naturally" protected from pregnancy by pregnancy and postpartum amenorrhoea. Their analysis clearly shows that throughout this period young single women became sexually active at increasingly younger ages. The proportion of woman years "protected" from pregnancy by virginity fell from $80 \%$ in the late 1980 s to $72 \%$ in the late 1990 s. Contraceptive use also increased but did not fully offset the rise in sexual activity (fig 2). As a result, the annual incidence of premarital conception in all women aged 15-24 years rose from 39 per 1000 woman years in 1986-90 to 49 in 1995-99. Among contraceptive users, the contribution of condoms to overall protection rose from $8.2 \%$ in the period $1986-1990$ to $22.1 \%$ in 1996-2000 (among all women, condom use went from $1.5 \%$ to $5.8 \%$ in that same period). Figure 3 shows this change over time. Although this increase in condom use did offset the increase in sexual activity and a higher proportion of acts were dually protected than before, the level of dual protection continued to be unacceptably low.

The 1996 DHS round included a module exclusively devoted to men's behaviour and attitudes towards reproductive health. ${ }^{5}$ One outcome measured was the lifetime number of partners. Four or more partners were reported by $6.1 \%$ of

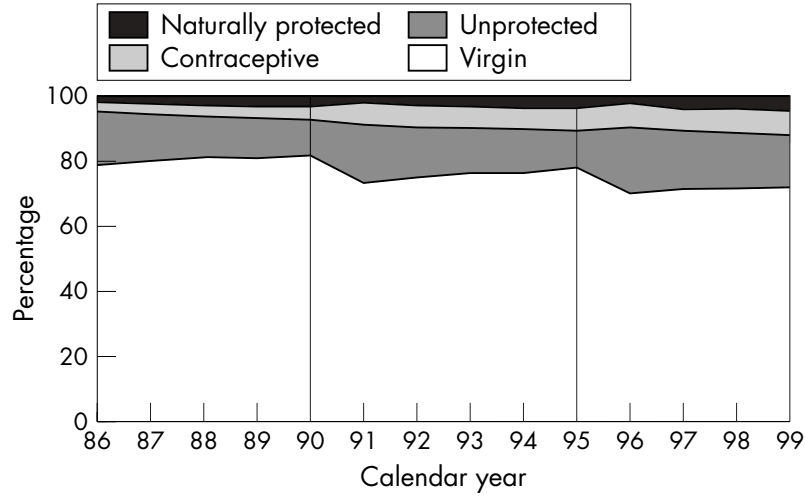

Figure 2 Trends in risks of conception among single women aged 15-24 years, by calendar year, Peru. Reproduced with permission from Ali et al. ${ }^{9}$

all respondents. This proportion was inversely related to age, being 9.5\% among men aged 15-24 years but only $1.9 \%$ among men aged 45 years or older. This pattern suggests that younger generations are more sexually active than older generations, although age related recall error is an alternative explanation. Additionally, those with higher education also reported a greater number of partners. Condom use at last sexual intercourse was again inversely related to age: $33.9 \%$ of men aged 15-24 years reported use compared with $9.3 \%$ of men aged 45 years or more. Regrettably, this module was not included in the year 2000 survey, so trends cannot be assessed. We can, however, compare men and women with regard to age at first union and age at first intercourse. In table 3 we show values of these indicators for women in years 1992, 1996, and 2000 and for men in year 1996. Changes over time have been small for women in both indicators; men start sex at ages 2.5 years younger than those of women, and start unions at ages four years older than those of women. Women tend to marry or cohabit within 1.5-2.5 years after first sex, whereas among men the difference in median ages at first intercourse and at first union was eight years in 1996.

Although the 2000 DHS did not include men, it included new questions addressing women's risk. Less than $1 \%$ of women reported more than one partner in the past 12 months.

\section{Special studies}

Studies have focused on both behavioural and biological outcomes in FSWs, MSM, the general population (sampled either in household probability samples or in health facilities), and mobile populations. Most have been conducted in

Table 3 Trends in women's age at first marriage/cohabitation and age at first sexual intercourse, and 1996 estimates for men

\begin{tabular}{|c|c|c|c|c|c|c|c|c|c|}
\hline \multirow{3}{*}{$\begin{array}{l}\text { Exact age by which } \\
\text { event experienced }\end{array}$} & \multicolumn{6}{|c|}{ Percentage of women (aged 25-49 years) } & \multirow{3}{*}{$\begin{array}{l}\text { Exact age by which } \\
\text { event experienced }\end{array}$} & \multirow{2}{*}{\multicolumn{2}{|c|}{$\begin{array}{l}\text { Percentage of men } \\
\text { (aged 25-59 years) } \\
1996\end{array}$}} \\
\hline & \multicolumn{2}{|l|}{1992} & \multicolumn{2}{|l|}{1996} & \multicolumn{2}{|l|}{2000} & & & \\
\hline & Marriage & First sex & Marriage & First sex & Marriage & First sex & & Marriage & First sex \\
\hline 15 years & 4.6 & 8.8 & 5.3 & 9.2 & 4.5 & 8.3 & 15 & NA & 20.8 \\
\hline 18 years & 24.2 & 36.6 & 24.7 & 39.0 & 23.4 & 38.2 & 18 & NA & 66.4 \\
\hline 20 years & 41.3 & 55.0 & 42.1 & 58.2 & 39.2 & 58.2 & 20 & 14.4 & 84.9 \\
\hline 25 years & 71.8 & 81.3 & 72.3 & 82.2 & 68.8 & 82.2 & 25 & 52.2 & 95.4 \\
\hline Never/not yet & 13.4 & 7.4 & 11.5 & $\begin{array}{l}0.9 \\
5.9\end{array}$ & 14.1 & 6.5 & Never/not yet & 16.1 & 0.7 \\
\hline Median age & $\begin{array}{l}10.4 \\
21.1\end{array}$ & 19.4 & 20.9 & 18.9 & 21.4 & 19.0 & Median age & 24.7 & 16.8 \\
\hline $\begin{array}{l}\text { Difference in median ages } \\
\text { of marriage and first sex }\end{array}$ & \multicolumn{2}{|c|}{1.7} & \multicolumn{2}{|c|}{2} & \multicolumn{2}{|c|}{2.4} & $\begin{array}{l}\text { Difference in median ages } \\
\text { of marriage and first sex }\end{array}$ & \multicolumn{2}{|c|}{7.9} \\
\hline
\end{tabular}

Source: DHS 1996 and $2000 .^{56}$

NA, not applicable. 


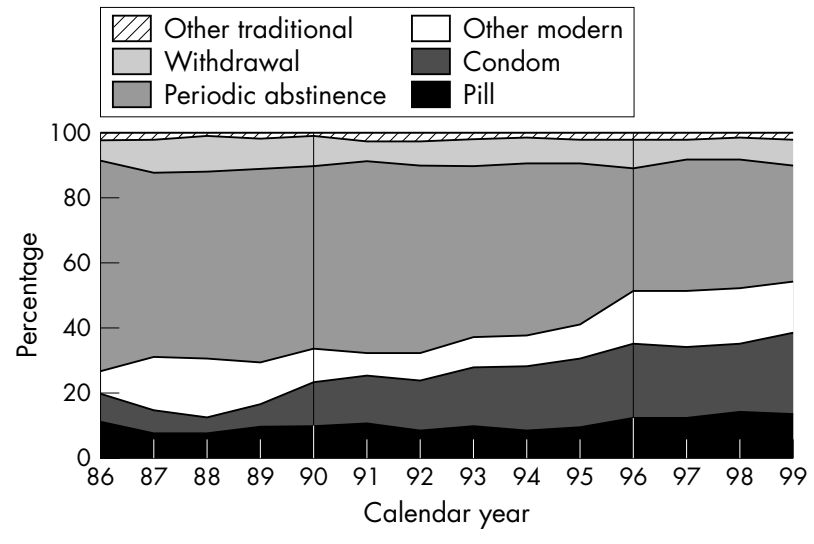

Figure 3 Trends in contraceptive protection by method among single women aged 15-24 years, by calendar year, Peru. Reproduced with permission from Ali et al. ${ }^{9}$

Lima, the Peruvian capital. Only two of the studies reviewed report cohorts of FSWs being followed up for at least some months. ${ }^{10}{ }^{11}$ Moreover, with the exception of two studies conducted in the late 1980s and in the mid 1990s, all the rest have been conducted from 1998 onwards, revealing a recent but increasing interest in the behavioural correlates of the HIV/AIDS epidemic.

Among studies focused on FSWs, Golenbock et al reported a low use of condoms, no HIV infection, but very high rates for other STIs. ${ }^{12}$ A much more recent study also found no HIV cases in FSWs or clients. ${ }^{13}$ Paris et al found that STI prevalence was not related either to numbers of partners or perceptions of AIDS as a threat. ${ }^{14}$ Two studies showed that consistent use of condoms-considered an achievable goal among FSWs - was associated with reduced transmission of STIs. ${ }^{10} 11$

Only one published paper focused on behavioural correlates of HIV infection among MSM. ${ }^{15}$ This was a cross sectional study where participants were recruited through street outreach. HIV and syphilis prevalences were high, especially among transvestites. Bisexuals were less likely to have used condoms consistently during the past year for vaginal sex than for insertive anal sex with men. The high prevalence of bisexual activity and low rates of consistent condom use, especially with female sexual partners, indicates a high vulnerability to HIV among bisexually active men. However, this might not result in a wider heterosexual epidemic provided that their female partners are monogamous.

Studies in the general population have been limited to cross sectional surveys which are not necessarily comparable. The study by McCarthy et al was based on 140976 biospecimens collected between 1986 and 1990 in the only laboratory performing HIV testing at the time. ${ }^{16}$ Although large, this was not a probability sample; rather, it was a collection of sera of various origins in Peru (symptomatic patients, people seeking voluntary counselling and testing, military recruits, blood donors, and so on) and confirmed expected high prevalence in certain subgroups. Conducted among those seeking health certificates, another study reported higher mean lifetime numbers of partners in males than in females (10.6 v 1.1), although the latter had STI prevalence 2.8 times higher than men. Unprotected sex with FSWs also implied higher risk among men. ${ }^{17}$ Specific populations such as male motorcycle drivers in Iquitos, a city in the Peruvian rain forest, have also been the focus of research. ${ }^{18}$ In a convenience sample of these men, up to $62 \%$ reported a history of STI, concordant with the high risk behaviour reported.
Studies of adolescents and young people have been of special interest, as these populations are assumed to have a high rate of partner change. In a study of young people in Lima, ${ }^{19}$ important differences between men and women with regard to sexual behaviour emerged. Men had both more heterosexual and homosexual experiences, and reported higher consistent condom use, whereas females reported higher consistent contraceptive use. In a second study of young people, ${ }^{20} 1367$ men from three inner cities in Peru (Chiclayo on the coast, Cuzco in the highlands, and Iquitos in Amazonia) were interviewed, and provided blood samples for HIV testing. Consistent condom use was low with both steady and casual partners of either sex. In general, this study suggested that HIV epidemics in inner Peruvian cities were at an early phase. Men's sexual behaviour was somewhat less risky in Cuzco than in Iquitos, in accordance with cultural patterns in the three regions of Peru (that is, more "conservative" in the highlands and more "liberal" in Amazonia), and also reflecting the epidemiological distribution of AIDS cases.

In recent years, studies have focused on "bridge populations" - that is, on groups implicated in HIV transmission from high prevalence to low prevalence populations. A recently published cross sectional study recruited participants from brothels and street based sex venues in Lima and Callao. They evaluated the risk behaviours and prevalence of gonorrhoea and chlamydia in 407 men in steady heterosexual relationships who also had sex with FSWs. ${ }^{21}$ Nearly all $(95.8 \%)$ of the participants reported using a condom in their most recent commercial intercourse, and $85.8 \%$ reported always using condoms with FSWs. Half (50.8\%) always used condoms with casual non-commercial partners but only $12 \%$ always used condoms with their stable partners. Of the $24.8 \%$ who also had sex with men, $59.6 \%$ always used condoms in homosexual anal sex. This study concluded that it is unlikely that these men constitute a bridging population spreading chlamydia or gonorrhoea from a core group of FSWs into the general low risk population.

One study among women giving birth in the largest maternity hospital in Lima showed that, among women, HIV infection was related both to their risk behaviours and to the perceived risk behaviours of their sexual partners, namely sex with FSWs or with other men. ${ }^{22}$ Another study focused on sexual networking and its relation with HIV infection: after interviewing 75 seropositive women at the same maternity hospital in Lima, risk among pregnant women was shown to depend largely upon their male partners' risk behaviours, indicating that monogamous women might be connected to very large sexual networks. ${ }^{23}$

A long term evaluation of trends in treatment of STD by private physicians has been recently conducted by Garcia et al. ${ }^{24}$ The number of first visits for pelvic inflammatory disease and trichomoniasis, and total visits for genital herpes showed an increase from 1983-85 to 1996-97, while first visits for gonorrhoea and total visits for syphilis have changed little in recent years. This form of active surveillance may, therefore, provide information of potential use in guiding policies for the prevention and management of STDs and HIV infections in developing countries.

Finally, a focus on mobile populations has emerged, as shown by two surveys of foreign tourists leaving the country. In a survey of visitors who were departing from Lima airport, sex with local partners was more frequent than sex with other travellers, and single males had high odds of having acquired new sex partners. Consistent use of condoms was reported by only $24 \%$ of respondents. ${ }^{25}$ In a similar study of travellers leaving from Lima and Cuzco airports, sex with local partners was reported by $40 \%$ of respondents. Homosexual and bisexual travellers were more likely to 
report three or more new sexual partners than heterosexual travellers. ${ }^{26}$

\section{CONCLUSIONS}

In part as a result of a tradition of research in both infectious diseases and population studies, studies of sexual behaviour in the era of HIV/AIDS are more numerous in Peru than elsewhere in South America (except Brazil). These studies have taken place in the epidemiological surveillance unit of the $\mathrm{MoH}$ (under a mandate to perform second generation HIV surveillance), in the context of new rounds of the DHS, and in academic research conducted in collaboration with international researchers.

Second generation behavioural surveillance components are at early stages of development, and, in any event, resources in the $\mathrm{MoH}$ have not been sufficient to process behavioural data (which have been collected in about half of the studies). A focus on studying as many populations as possible has been observed, and in all cases measuring and reporting HIV and STI prevalence have been given priority. Studies have been conducted at various points in time, which makes possible an initial trend analysis. However, the continuation of funding for these studies is uncertain. More resources are needed to strengthen behavioural data collection (that is, protocol and instrument design) and analysis in conjunction with STI prevalence estimation. Another, more basic, concern is the need to assess the representativeness of sentinel study samples-such as ANC patients-as a proxy for the general female population, or health service and street based samples of MSM as a proxy for all MSM.

The various rounds of the DHS in Peru also constitute an invaluable resource for studies in the demography and family planning fields. Their usefulness as a source of information relevant to assessing behavioural trends regarding HIV related risks is limited, particularly as the men's module introduced in 1996 was dropped in 2000 due to cost. Nevertheless, a greater effort to analyse traditional demographic variables from an HIV risk perspective, as well as the increasing inclusion of questions relevant to HIV risk, can make the large and highly representative samples of the DHS more useful in this field. The examples of behavioural comparisons between men and women presented here are particularly helpful in showing gender based risk differences, as well as in suggesting that women's risks in Peru are mainly dependent on the behaviours of their male partners. Ideally, then, a men's module should be restored.

Finally, published reports of academic studies, although more focused, generally provide rigorous epidemiological analyses of the contexts they assess. They tend to confirm that the Peruvian epidemic is concentrated on MSM, with a still low HIV prevalence among FSWs and even lower rates (below $0.5 \%$ ) in the general population. They have also confirmed that the risks faced by women are strongly related to those of male partners, such as sex with FSWs or with men. Obviously, their specific focus makes them unsuitable for regular trend monitoring.

In spite of the limitations outlined above, the availability of data offers opportunities for more in-depth analyses, which could provide better evidence for public health policies. They could also establish the foundation of new, more productive studies that respond to emerging needs-such as the follow up of the Millennium Goals, the UNGASS on AIDS goals, and the National Plan supported by the Global Fund on AIDS, TB, and Malaria.

\section{ACKNOWLEDGEMENTS}

We thank the Ministry of Health (and in particular Dr Luis Suárez and Dr Mónica Pun from the Office of Epidemiology) for providing their surveillance database for analysis. We thank Professor John Cleland for his extremely important suggestions to earlier versions of this paper.

\section{CONTRIBUTORS}

CC coordinated the study, consolidated the first draft of the manuscript, and incorporated changes as discussed with WM. WM contributed to study design, data collection, and analysis, wrote sections of the manuscript, and made suggestions to the paper drafts.

\section{Authors' affiliations}

C F Cáceres, W Mendoza, School of Public Health, Cayetano Heredia University, Lima, Peru

W Mendoza, Instituto de Investigación Nutricional, Lima, Peru

\section{REFERENCES}

1 UNAIDS/WHO Working Group on Global HIV/AIDS and STI Surveillance. Guidelines for second generation HIV surveillance. Geneva: WHO and the Joint UN Programme on HIV/AIDS, 2000.

2 McGarrigle CA, Fenton KA, Gill AN, et al. Behavioural surveillance: the value of national coordination. Sex Transm Infect 2002;78:398-405.

3 Family Health International. Behavioral Surveillance System BSS. Guidelines for repeated behavioral surveys in populations at risk of HIV, 2000.

4 Ministerio de Salud. HIV-AIDS Surveillance Database, Lima, 2003.

5 INEI and Macro International Inc. Peru-encuesta demográfica y de salud familiar, 1996. Calverton, Maryland, 1997.

6 INEI and Macro International Inc, USAID and UNICEF. Peru-encuesta demografica y de salud familiar 2000. Lima, 2001.

7 Filmer $\mathbf{D}$. The socioeconomic correlates of sexual behaviour: a summary of results from an analysis of DHS data. In Confronting AIDS Pandemic, World Bank, 1997.

8 INEI/Asociación Benéfica PRISMA/Demographic and Health Surveys, Macro International Inc. Perú-encuesta demográfica y de salud familiar 1991-92. ENDES 1991-92, Lima, 1992

9 Ali M, Cleland J, Shah I. Trends in reproductive behaviour among young single women in Colombia and Peru: 1985-99. Demography 2003;40:659-73

10 Sanchez J, Gotuzzo E, Escamilla J, et al. Sexually transmitted infections in female sex workers: reduced by condom use but not by a limited periodic examination program. Sex Transm Dis 1998;25:82-9.

11 Sanchez J, Campos PE, Courtois B, et al. Prevention of sexually transmitted diseases in female sex workers: prospective evaluation of condom promotion and strengthened STD services. Sex Transm Dis 2003;30:273-9.

12 Golenbock DT, Guerra J, Pfister J, et al. Absence of infection with human immunodeficiency virus in Peruvian prostitutes. AIDS Res Hum Retroviruses 1988:4:493-9.

13 Trujillo L, Muñoz D, Gotuzzo E, et al. Sexual practices and prevalence of HIV, HTLV-I/II, and Treponema pallidum among clandestine female sex workers in Lima, Peru. Sex Transm Dis 1999;26:115-18.

14 Paris M, Gotuzzo E, Goyzueta G, et al. Prevalence of gonococcal and chlamydial infections in commercial sex workers in a Peruvian Amazon City. Sex Transm Dis 1999;26:103-7.

15 Tabet S, Sanchez J, Lama J, et al. HIV, syphilis, and heterosexual bridging among Peruvian men who have sex with men. AIDS 2002;16:1271-7.

16 McCarthy MC, Wignall FS, Sanchez J, et al. The epidemiology of HIV-1 infection in Peru, 1986-1990. AIDS 1996;10:1141-5.

17 Sanchez J, Gotuzzo E, Escamilla J, et al. Gender differences in sexual practices and sexually transmitted infections among adults in Lima, Peru. Am J Public Health 1996;86:1098-107.

18 Paris M, Gotuzzo E, Goyzueta G, et al. Motorcycle taxi drivers and sexually transmitted infections in a Peruvian Amazon City. Sex Transm Dis 2001;28:11-13.

19 Cáceres CF, Marín BV, Hudes ES, et al. Young people and the structure of sexual risks in Lima. AIDS 1997;11(Suppl 1):S67-S77.

20 Cáceres CF, Mendoza W, Yon C, et al. SIDA en el Perú: imágenes de diversidad. University of Peru at Cayetano Heredia, REDESS Jóvenes, Lima, 1998.

21 Miller GA, Mendoza W, Krohn M, et al. Clients of female sex workers in Lima, Peru: a bridge population for STD/HIV transmission? Sex Transm Dis 2004:31:337-42.

22 Alarcón JO, Johnson KM, Courtois B, et al. Determinants and prevalence of HIV infection in pregnant Peruvian women. AIDS 2003;17:613-18.

23 Johnson KM, Alarcón J, Watts DM, et al. Sexual networks of pregnant women with and without HIV infection. AIDS 2003;17:605-12.

24 Garcia PJ, Hughes J, Carcamo C, et al. Training pharmacy workers in recognition, management, and prevention of STDs: district-randomized controlled trial. Bulletin WHO 2003;81:806-14.

25 Cabada MM, Echevarria Jl, Seas CR, et al. Sexual behavior of international travelers visiting Peru. Sex Transm Dis 2002;29:510-3.

26 Cabada MM, Montoya M, Echevarria Jl, et al. Sexual behavior in travelers visiting Cuzco. J Travel Med 2003;10:214-18. 